\title{
Analisis Karakteristik Pengunjung Obyek Wisata Kebun Raya Balikpapan
}

\author{
Rahmi Yorika $^{1 *}$, Rizky Arif Nugroho², Elin Diyah Syafitri ${ }^{3}$ \\ 1,2,3 Program Studi Perencanaan Wilayah dan Kota, Institut Teknologi Kalimantan
}

\author{
*Email: rahmiyorika@ lecturer.itk.ac.id
}

\begin{abstract}
In this study, the authors aims to analyze characteristics of visitor at the Balikpapan Botanical Gardens Tourism Object. This study aims to determine the characteristics of visitors based on demographic characteristics, physiological characteristics and characteristics of travel patterns. The method used is descriptive qualitative research method with a rationalistic approach based on data obtained through questionnaires. The research results obtained, the demographic characteristics of visitors to the Balikpapan Botanical Gardens are dominated by the unmarried young generation, aged 17-30 years and dominated by male gender. As many as 36\% of visitor respondents are students and university students. Physiological characteristics of visitors show that $98 \%$ of visitor respondents are tourists who make short visits $<12$ hours, and the largest budget allocation is for transportation so it is not consumptive. Based on the characteristics of the travel pattern, it was found that the majority of visitors $197.2 \%$ of respondents) were group visitors who arranged their own trips without the help of a travel agency for vacation purposes and the dominant vehicle preferences were using cars and motorbikes.
\end{abstract}

Keywords : Botanical Gardens, Tourism, Visitor, Characteristic

\begin{abstract}
Abstrak
Dalam penelitian ini penulis menganalisis karakteristik pengunjung Objek Wisata Kebun Raya Balikpapan, penelitian ini bertujuan untuk mengetahui karakteristik pengunjung berdasarkan karakteristik demografis, karakteristik fisiologis dan karakteristik pola perjalanan. Metode yang digunakan yaitu, metode penelitian deskriptif kualitatif dengan pendekatan rasionalistik berdasarkan data yang didapatkan melalui kuesioner. Hasil penelitian yang didapatkan, maka karakteristik demografis pengunjung Kebun Raya Balikpapan didominasi oleh generasi muda belum menikah, berusia 17-30 tahun dan didominasi oleh jenis kelamin laki-laki. Sebanyak 36\% dari responden pengunjung merupakan pelajar dan mahasiswa. Karakteristik pengunjung secara fisiologis diperoleh hasil bahwa $98 \%$ responden pengunjung adalah wisatawan yang melakukan kunjungan singkat $<12 \mathrm{jam}$, dan alokasi anggaran terbesar adalah untuk transportasi sehingga tidak konsumtif. Berdasarkan karakteristik pola perjalanannya, diperoleh hasil bahwa mayoritas pengunjung ( $97,2 \%$ responden) merupakan pengunjung rombongan yang mengatur perjalanannya sendiri tanpa bantuan biro perjalanan dengan tujuan liburan dan preferensi kendaraan dominan adalah menggunakan mobil dan sepeda motor.
\end{abstract}

Kata kunci : Karakteristik, Kebun Raya, Pengunjung, Wisata

\section{Pendahuluan}

Salah satu sektor yang dapat dikembangkan untuk untuk memperoleh Pendapatan Asli Daerah (PAD) adalah sektor pariwisata. Pemerintah Kota Balikpapan menargetkan kunjungan wisatawan sebanyak 2,9 juta, sehingga pengembangan destinasi wisata mutlak diperlukan untuk mencapai target tersebut. Beberapa destinasi wisata unggulan yang ada di Kota Balikpapan yaitu Pantai Manggar, Kebun Raya Balikpapan, Hutan Lindung Sungai Wain, Mangrove Center dan wisata belanja. Kebun Raya Balikpapan merupakan salah satu destinasi wisata yang berpotensi untuk dikembangkan karena hingga saat ini peruntukannya masih sebatas dijadikan penelitian 
alami. Kebun Raya Balikpapan yang didirikan pada tahun 2014 memiliki luas 300 hektar. Pengembangan Kebun Raya Balikpapan turut mendukung rencana Pemerintah Daerah Kalimantan Timur untuk mengembangkan sektor pariwisata di Kalimantan Timur. Oleh karena itu, perlu disusun konsep pengembangan Kebun Raya Balikpapan agar mampu menarik wisatawan untuk berkunjung ke sana. Konsep pengembangan tersebut harus disesuaikan dengan karakteristik pengunjung Kebun Raya Balikpapan agar tepat sasaran.

Beberapa permasalahan yang berkaitan dengan pengembangan pariwisata Kota Balikpapan adalah tentang pengembangan sumber daya manusia, bukan hanya persoalan sarana dan prasarana. Terkait kondisi sumber daya manusia, dari 8 kelompok sadar wisata yang ada di Kota Balikpapan, hanya 6 kelompok sadar wisata yang aktif. Selain itu, Kebun Raya Balikpapan sendiri yang masih bertujuan sebagai ruang penelitian alami, belum banyak memiliki fasilitas hiburan yang tersedia seperti wahana bermain, wisata kuliner, atau binatang eksotis. Sehingga tingkat kunjungannya ratarata hanya 20 orang pada saat liburan (Lapian, 2018). Karakteristik pengunjung merupakan hal yang penting terkait suatu objek wisata. Pemahaman akan karakter dan tipologi pengunjung suatu wisata akan berpengaruh dalam melakukan perencanaan serta strategi pengembangan obyek wisata (Pitana, 2005).

Tujuan penelitian ini adalah untuk melakukan analisis terkait karakteristik wisatawan yang datang berkunjung ke Kebun Raya Balikapapan berdasarkan karakteristik demografis, karakteristik fisiologis dan pola perjalanan melalui analisis statistika deskriptif, yang diharapkan dapat menjadi bahan masukan bagi pengelolaan Kebun Raya Balikpapan sehingga bisa meningkatkan jumlah pengunjung. Karakteristik pengunjung merupakan salah satu komponen yang berpengaruh untuk menyusun rencana pengelolaan suatu objek pariwisata, begitupun dengan Kebun Raya Balikpapan. Dengan mengetahui bagaimana karakteristik dari pengunjungnya dapat disusun konsep pengembangan Kebun Raya Balikpapan. Penelitian ini bertujuan untuk menganalisis karakteristik pengunjung Kebun Raya Balikpapan berdasarkan karakteristik demografis, fisiologis, dan pola perjalanan.

\section{Destinasi Wisata}

Sebuah destinasi wisata dapat diartikan sebagai kawasan yang memiliki batas geografi tertentu yang memiliki kompenen suatu produk pariwisata, layanan, jaringan fungsional sehingga akan memberikan pengalaman berkunjung (Lubis, 2018). Daya tarik wisata menurut UndangUndang Republik Indonesia Nomor 10 tahun 2009 adalah daya tarik wisata dijelaskan sebagai segala sesuatu yang memiliki keunikan, kemudahan, dan nilai yang berupa keanekaragaman kekayaan alam, budaya, dan hasil buatan manusia yang menjadi sasaran atau kunjungan wisatawan. Pendit (2002) juga mendefinisikan daya tarik wisata sebagai suatu sasaran wisata.

\section{Karakteristik Wisatawan}

Wisatawan didefinisikan secara beragam oleh para para ahli, Inskeep (1991) mendefinisikan wisatawan sebagai satu atau kelompok orang yang mengunjungi suatu tempat tertentu baik negara, propinsi, perkotaan ataupun desa yang berbeda lokasinya dari lokasi tempat tinggal mereka. Dengan tujuan bukan untuk mendapat mata pencaharian. Wisatawan ,disini dibagi menjadi wisatawan temporer yaitu yang menetap sedikitnya 24 jam di lokasi kunjungan dan pelancong, yaitu wisatawan temporer yang menetap kurang dari 24 jam di lokasi kunjungan dan biasanya tidak menginap. Undang-Undang No. 9 Tahun 1990 tentang Kepariwisataan, mendefinisikan wisatawan sebagai orang yang melakukan wisata. 
Karakteristik wisatawan, menurut Seaton dan Bennet (1996) terbagi atas 2 karateristik umum, yaitu berdasarkan karakteristik perjalanannya (trip descriptor) dan karakteristik wisatawannya (tourist descriptor). Pada karakteristik trip descriptor, wisatawan akan dibagi berdasarkan jenis perjalanan yang dilakukananya sementara tourist descriptor akan memfokuskan karakteristiknya langsung kepada wisatawannya, terkait siapa, apa yang diinginkan , kenapa, kapan, dan dimana.

Sedangkan Menurut Smith (1995) terdapat 2 jenis karakteristik wisatawan yaitu

1. Karakteristik Sosio-Demografis yang merupakan pembagian karakteristik paling sering dipaki untuk kepentingan analisis pariwisata, perencanaan dan pemasaran.

2. Karakteristik psikografis, mengklasifikasikan wisatawan ke dalam kelompok-kelompok yang berhubungan dengan kelas sosial, life-style dan karakteristik personal. Karakteristik wisatawan berdasarkan psikografi lebih menekankan pada motivasi yang melatarbelakangi perjalanan, yang didalamnya terdapat beberapa indikator antara lain: Keinginan berinteraksi dengan masyarakat, keinginan tujuan melakukan perjalanan untuk bersenangsenang, objek wisata yang dikunjungi sudah dikenal dikalangan masyarakat, berwisata dengan sedikit orang, melakukan banyak kegiatan wisata, menginginkan fasilitas wisata yang lengkap, sikap dan aksi baik di tempat wisata, memiliki pengetahuan tentang objek dikunjungi, menyesuaikan gaya hidup dengan tempat wisata serta keamanan dan kenyaman dalam memilih tempat wisata.

Analisis karakteristik wisatawan juga dapat dilakukan berdasarkan karakteristik sosiodemografis, geografis dan psikografis yang dimilikinya. Yang termasuk dalam karakteristik sosiodemografis diantaranya adalah jenis kelamin, umur, status perkawinan, tingkat pendidikan, pekerjaan, kelas sosial, ukuran keluarga atau jumlah anggota keluarga dan lain-lain yang dielaborasi dari karakteristik tersebut. Selain itu, dapat dilihat pula dari karakteristik geografis dan psikografis dimana karakteristik geografis membagi wisatawan berdasarkan lokasi tempat tinggalnya, biasanya dibedakan menjadi desa-kota, propinsi, maupun negara asalnya. Sedangkan karakteristik psikografis membagi wisatawan ke dalam kelompok-kelompok berdasarkan kelas sosial, life-style dan karakteristik personal (Nugroho, 2019).

\section{Metodologi}

\subsection{Jenis dan Pendekatan}

Berdasarkan rumusan masalah yang diteliti, maka metode yang digunakan pada penelitian ini adalah metode deskriptif kualitatif dengan pendekatan rasionalistik. Metode kualitatif melihat hubungan antara variabel pada obyek penelitian sebagai hubungan yang bersifat interaktif dan saling mempengaruhi dan tidak melakukan generalisasi tapi lebih menekankan pada makna dan kedalaman informasi. Prosedur penelitian kualitatif akan menghasilkan data deskriptif berupa katakata tertulis dan lisan dari perilaku dan obyek penelitian. Metode kualitatif dengan pendekatan rasionalistik, akan memberikan kesempatan kepada peneliti untuk bertindak sebagai instrument utama di dalam penelitian dan melakukan interviu kepada obyek penelitian sehingga diperoleh informasi, perkembangan, fenomena, ataupun perubahan-perubahan yang mungkin terjadi.

Pengambilan data penelitian ini dilakukan dengan teknik penyebaran kuesioner, yaitu merupakan suatu metode untuk memperoleh data yang dilakukan dengan cara membuat suatu daftar pertanyaan. Daftar pertanyaan ini nantinya akan disebarkan dan diisi oleh responden yaitu orang/pengunjung yang berkunjung ke area wisata Kebun Raya Balikpapan selama periode minggu ke 4 pada Bulan Agustus 2020. Hasilnya kemudian akan dianalisis menggunakan metode statistika 
deskriptif dimana metode ini merupakan cara analisis untuk mendeskripsikan, menggambarkan, menjabarkan, atau menguraikan data agar mudah dipahami (Siregar, 2010).

\subsection{Variabel dan Responden}

Variabel yang digunakan pada penelitian ini terkait karakteristik demografis pengunjung ialah usia, jenis kelamin, pendidikan, pendapatan, mata pencaharian dan status perkawinan. Variabel terkait karakteristik fisiologis penduduk yaitu lama kunjungan dan alokasi anggaran yang disiapkan untuk berkunjung. Sementara, variabel terkait karakteristik pola perjalanan adalah jumlah peserta kunjungan, tujuan kunjungan, penyelenggara perjalanan, dan preferensi moda transportasi.

Penelitian ini diawali dengan tinjauan pustaka serta pengumpulan data sekunder kemudian pembuatan kuesioner. Kuesioner dibagikan kepada responden secara purposive sampling dengan ketentuan bahwa responden berusia 17 tahun keatas dan pernah 1 kali mengunjungi obyek wisata Kebun Raya Balikpapan dalam 2 tahun terakhir. Jumlah responden yang berhasil didata selama periode penyebaran kuesioner berjumlah sebanyak 74 orang.

\section{Hasil dan Pembahasan}

\subsection{Karakteristik Demografis}

Berdasarkan aspek demografis, karakteristik pengunjung pada Kebun Raya Balikpapan dapat dilihat pada tabel 1

Tabel 1 Karakteristik demografis pengunjung

\begin{tabular}{lll}
\hline Jenis Kelamin & Laki-Laki & $68.5 \%$ \\
\hline Usia & Perempuan & $31.5 \%$ \\
\hline & $17-<20$ tahun & $45.3 \%$ \\
\hline & $20-30$ tahun & $48.3 \%$ \\
\hline Status Perkawinan & $30-40$ tahun & $4.1 \%$ \\
\hline & $>40$ tahun & $2.3 \%$ \\
\hline Pendidikan terakhir & Belum kawin & $97.3 \%$ \\
\hline & Kawin & $2.7 \%$ \\
\hline Pekerjaan pengunjung & Perguruan Tinggi & $27.4 \%$ \\
\hline & SMA sederajat & $72.6 \%$ \\
\hline & Pelajar dan mahasiswa & $36 \%$ \\
\hline & Wiraswasta & $22 \%$ \\
\hline & Karyawan & $13 \%$ \\
\hline & Freelance & $11 \%$ \\
\hline & PNS/TNI/POLRI & $5 \%$ \\
\hline & Lain-Lain & $13 \%$
\end{tabular}

Pengunjung lebih didominasi oleh pengunjung laki-laki sebanyak 68,5\% dibandingkan dengan pengunjung perempuan. Rentang usia pengunjung terbanyak pada rentang usia 17-30 tahun dan sangat sedikit sekali pengunjung yang berusia 40 tahun keatas, yaitu hanya $2,3 \%$ dari total responden. Sementara untuk pendidikan terakhir dari pengunjung, sebanyak 72,6\% adalah lulus SMS/sederajat dan sisanya berasal dari perguruan tinggi. Untuk variabel pendidikan, sebanyak $36 \%$ pengunjung adalah pelajar dan mahasiswa serta $22 \%$ adalah wiraswasta. Berdasarkan karakteristik pengunjung secara demografis, dapat diketahui bahwa dominasi pengunjung berasal dari anak muda dengan rentang usia 17 hingga 30 tahun dan didominasi oleh jenis kelamin lakilaki. Pengunjung berada pada rentang usia muda. Kebun Raya Balikpapan berlokasi didekat 
Kampus ITK, sehingga sangat berpotensi dikunjungi oleh para mahasiswa ITK, yang kos/bertempat tinggal didekat wisata. Sebagai wisata alam, Kebun Raya Balikpapan sebenarnya sangat cocok untuk dijadikan arena rekreasi keluarga, sayangnya hanya 2,7 \% dari responden pengunjung yang statusnya sudah menikah, hal ini menunjukkan masih rendahnya pengunjung yang menjadikan Kebun Raya sebagai sarana wisata keluarga. Hal ini dapat menjadi evaluasi bagi pengelola Kebun Raya Balikpapan, untuk meningkatkan promosi wisatanya dengan branding wisata alam keluarga sehingga bisa meningkatkan jumlah pengunjung. Menurut Ingkadijaya et al (2016), wisata alam keluarga merupakan salah satu alternatif wisata keluarga yang memiliki frekuensi aktivitas tinggi.

\subsection{Karakteristik Fisiologis}

Hasil penelitian terkait karakteristik pengunjung Kebun Raya Balikpapan berdasarkan pola perjalanan dapat dilihat pada gambar 1.

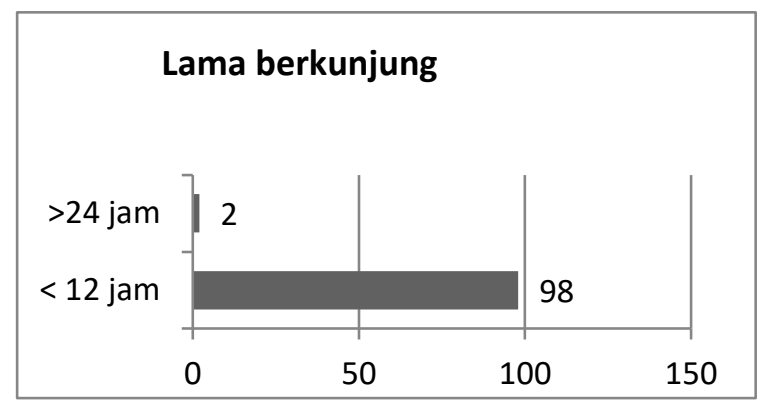

Gambar 1. Lama kunjungan (analisis pengunjung, 2020)

Sebanyak $98 \%$ responen, memiliki lama berkunjung kurang dari 12 jam, hanya $2 \%$ saja yang berkunjung lebih 24 jam. Pengunjung yang datang kebanyakan hanya untuk melakukan kunjungan pendek kecuali peneliti yang memang ada keperluan terkait penelitiannya. Berdasarkan penelitian, mayoritas responden mengalokasikan anggarannya untuk transportasi, restoran, dan cendera mata dengan alokasi dana terbesar adalah untuk transportasi. Sedangkan untuk memasuki Kebun Raya Balikpapan sendiri tidak membutuhkan biaya, karena memang tidak ada pembayaran untuk tiket masuk. Dominasi pengunjung yang datang, adalah tipe pengunjung tidak konsumtif dengan durasi kunjungan yang singkat. Hal ini juga dipengaruhi kurangnya fasilitas dan atraksi yang dapat dinikmati oleh pengunjung. Kebun Raya Balikapan memiliki, kafetaria tetapi belum dikelola secara optimal. Dengan pengelolaan yang optimal, kafetaria dapat menjadi salah satu daya tarik wisata dan memberikan pemasukan untuk pengelola Kebun Raya Balikpapan. Selain itu, dengan adanya kafetaria maka akan meningkatkan interaksi antara pengunjung dengan lingkungan sekitarnya melalui konsep yang tepat. Hal ini akan menjadikan pengalaman wisata pengunjung akan lebih berkesan (Martins et al, 2017). 


\subsection{Pola Perjalanan}

Hasil penelitian terkait karakteristik pengunjung Kebun Raya Balikpapan berdasarkan pola perjalanan dapat dilihat pada gambar 2.

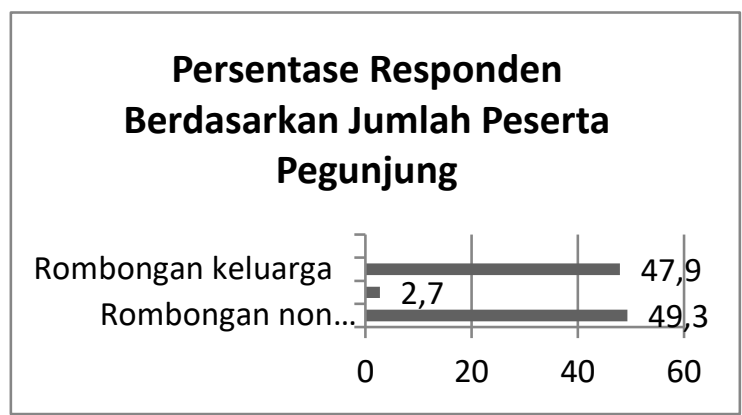

a

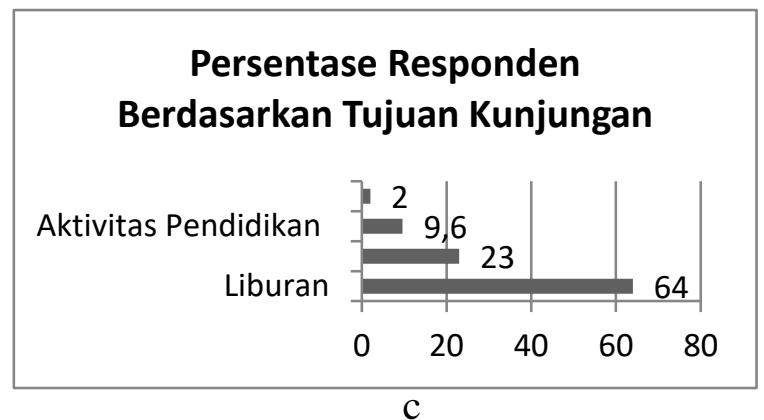

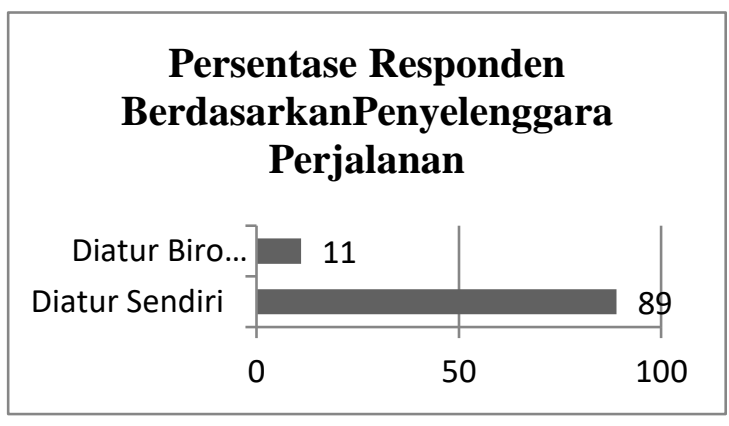

b

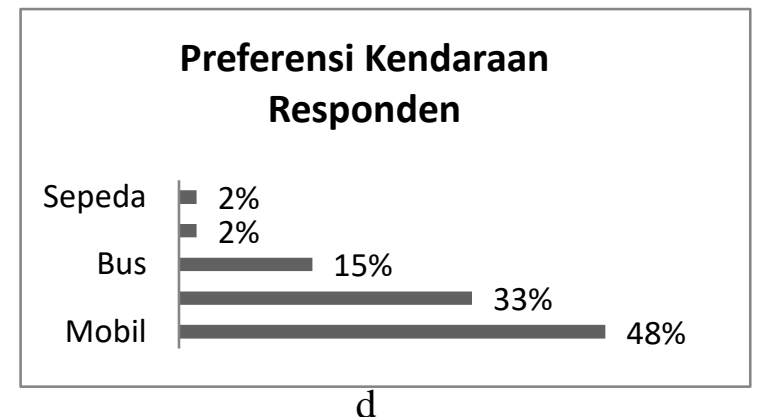

Gambar 2. Karakteristik pola perjalanan pengunjung (analisis penulis, 2020)

Berdasarkan karakteristik pola perjalanan dari pengunjung Kebun Raya Balikpapan, sangat sedikit sekali responden pengunjung yang datang perorangan/sendirian yaitu hanya $3 \%$ dari total responden. Pengunjung didominasi oleh rombongan, baik itu rombongan keluarga maupun rombongan non keluarga. Sebagian besar responden (89\%) yang datang juga menyelenggarakan perjalanannya sendiri tanpa bantuan biro perjalanan. Untuk tujuan kunjungan, sebanyak 64\% responden, menyebut tujuan kunjungannya adalah liburan, 23\% pengenalan lingkungan, 9,3\% aktivitas pendidikan dan sedikit sekali yang datang berkunjung terkait kunjungan kerja. Kebun Raya Balikpapan, menawarkan wisata alam yang asri dengan udara yang segar sehingga memang sangat cocok untuk dijadikan destinasi liburan, untuk mengusir kepenatan. Posisi Kebun Raya Balikpapan yang berdekatan dengan kampus negeri sebenarnya sangat berpotensi untuk menarik pengunjung dari kalangan mahasiswa. Hutan konservasi yang dimiliki oleh Kebun Raya Balikapan, sangat cocok untuk menjadi tujuan wisata edukasi bagi pelajar sekaligus tempat penelitian bagi mahasiswa. Sayangnya, baru $9,6 \%$ dari responden yang datang untuk melakukan aktivitas pendidikan. Jika melihat preferensi kendaran yang dipilih oleh responden, sebanyak $48 \%$ responden menggunakan mobil dan 33\% menggunakan sepeda motor serta hanya sebagian kecil yaitu $2 \%$ saja yang menggunakan kendaraan umum online.

Untuk mencapai langsung kedalam kebun raya memang tidak ada trayek kendaraan umum khusus, sehingga penggunaan kendaraan pribadi lebih dominan. Selain itu, pada area wisata juga sulit ditemukan kendaraan umum online. Banyaknya responden yang menggunakan sepeda motor juga mengindikasikan bahwa dominasi pengunjung adalah pengunjung lokal. Kondisi ini seharusnya menjadi bahan evaluasi bagi pengelola Kebun Raya Balikpapan, karena kemudahan 
akses akan memberikan dampak positif terkait penambahan pengunjung. Berdasarkan Porto et al (2018), permintaan akan kunjungan sebuah destinasi wisata akan meningkat secara signifikan jika aksesibel.

\section{Kesimpulan}

Penelitian mengenai karakteristik pengunjung Kebun Raya Balikpapan, dilakukan melalui telaah terhadap karakteristik demografis pengunjung, karakteristik fisiologis dan karakteristik pola perjalanan. Berdasarkan karakteristik demografisnya dominasi pengunjung Kebun Raya Balikapan adalah generasi muda belum menikah, berusia 17-30 tahun dan didominasi oleh jenis kelamin lakilaki dengan karakteristik fisiologis berupa kunjungan singkat $<12$ jam, dan alokasi anggaran terbesar adalah untuk transportasi sehingga tidak konsumtif. Berdasarkan karakteristik pola perjalannya, sebagian besar respon adalah rombongan yang mengatur perjalannya sendiri dengan tujuan liburan dan preferensi kendaraan dominan adalah mobil dan motor.

\section{Saran}

Karakteristik Pengunjung akan menjadi suatu bahan evaluasi bagi pengelola Kebun Raya Balikpapan untuk menyusun program pengelolaan Kebun Raya Balikapan. Diperlukan adanya penelitian lebih lanjut terkait aksesibililitas kebun raya dan fasilitas yang tepat untuk menarik minat pengunjung.

\section{Ucapan Terimakasih}

Terimakasih kami sampaikan kepada pihak pengelola Kebun Raya Balikpapan atas dukungan yang diberikan sehingga penelitian ini bisa terlaksana.

\section{Daftar Pustaka}

Anonim. (2009). Undang-Undang Nomor 10 Tahun 2009 Tentang Kepariwisataan. Departemen Kementerian Pariwisata, Jakarta.

Anonim. (1990). Undang-Undang Nomor 9 Tahun 1990 Tentang Kepariwisataan. Departemen Kementerian Pariwisata, Jakarta.

Ingkadijaya, R., Damanik, J., Putra, H. S. A.., \& Nopirin. (2016). Aktivitas Wisata Pilihan Keluarga Perkotaan. Khasanah Ilmu-Jurnal Pariwisata Dan Budaya, 7(1).

Inskeep, Edward. (1991). Tourism Planning And Suistainable Development Approach. Van Nostrand Reinblod, New York.

Lapian, A. H. (2018). Diresmikan Sejak 2014, Begini Kondisi Kebun Raya Balikpapan Sekarang. Diakses pada 18 Agustus 2019 dari https://kaltim.tribunnews.com/2018/11/21/diresmikan-sejak-2014-beginikondisi-kebun-raya-balikpapan-sekarang.

Lubis, M. Z. M. (2018). Prospek Destinasi Wisata Halal Berbasis OVOP (One Village One Product). Maqdis: Jurnal Kajian Ekonomi Islam, 3(1), 31-47.

Nugroho, R. A. (2019). Karakteristik Wisatawan Nusantara yang Berkunjung ke Kota Solo. Jurnal Kepariwisataan Indonesia, 13(2), 25-35.

Martins, J., Goncalves, R., Branco, F., Barbosa, L., Melo, M., \& Bessa, M. (2017). A Multisensory Virtual Experience Model For Thematic Tourism: A Port Wine Tourism Application Proposal. Journal of Destination Marketing \& Management, 6(2), 103-109. 
Pendit, Nyoman S. (2002). Ilmu pariwisata : Sebuah pengantar perdana. Jakarta Pradnya Paramita.

Pitana, I. G. dan Gayatri, P.G. (2005). Sosiologi Pariwisata. Yogyakarta.

Porto, N., Rucci, A. C., \& Ciaschi, M. (2018). Tourism accessibility competitiveness. A regional approach for Latin American countries. Investigaciones Regionales - Journal of Regional Research, 42, 7591.

Seaton, A.V \& Bennet M. (1996). The Marketing Tourism Products: Concepts, Issues and Cases. International Thomson Business Press: London. Sidharta.

Siregar, S. (2010). Statistika Deskriptif Untuk Penelitian, Jakarta: Rajawali Pers.

Smith, Stephen C.J. 1995. Tourism Analysis, A Handbook. Harlow, England, Longman Group Limited. 